\title{
(6) \\ Feasibility of precompetition medical assessment at FIFA World Cups for female youth players
} OPEN ACCESS

\author{
Jiri Dvorak, ${ }^{1,2}$ Katharina Grimm, ${ }^{1}$ Christian Schmied, ${ }^{3}$ Astrid Junge ${ }^{2,4}$
}

\begin{abstract}
${ }^{1}$ Fédération Internationale de Football Association (FIFA),

Zurich, Switzerland

${ }^{2}$ Schulthess Klinik, Zurich,

Switzerland

${ }^{3}$ Cardiovascular Centre, University Hospital Zurich, Zürich, Switzerland

${ }^{4}$ FIFA - Medical Assessment and Research Centre (F-MARC), Zürich, Switzerland
\end{abstract}

\section{Correspondence to}

Astrid Junge, FIFA - Medical Assessment and Research Centre (F-MARC), Lengghalde 2, Zürich, Switzerland; astrid. junge@kws.ch

Received 28 June 2011 Accepted 22 September 2011

Published Online First 21 October 2011
ABSTRACT

Background Although most experts agree that preparticipation screening is important to prevent sudden cardiac death in sport, only a few reports have been published on the feasibility of its practical implementation. Methods The football associations participating in the U-17 and U-20 Women's World Cups 2010 were asked to perform a standardised precompetition medical assessment (PCMA) of their players (in total 672).

Results Compliance with the requirement for performing the PCMA was high among all teams, particularly from African, Asian and Central/South American countries. No relevant abnormal findings in personal history and clinical cardiological examination were reported. Athletic ECG patterns were frequent, but very few findings were considered to require further investigation. All players were declared as eligible to play.

Conclusions Based on the demonstrated feasibility of performing a comprehensive PCMA in elite female youth players, the Fédération Internationale de Football Association (FIFA) Executive Committee decided to make the PCMA a compulsory requirement for all FIFA competitions.

\section{INTRODUCTION}

Although most experts agree that preparticipation screening is important, ${ }^{1-3}$ especially to prevent suddencardiac death(SCD) in sport, ${ }^{4-6}$ only a few reports on its implementation have been published. ${ }^{7-11}$ The Fédération Internationale de Football Association (FIFA) developed a standardised precompetition medical assessment (PCMA) and implemented it at the Men's 2006 FIFA World Cup ${ }^{9} 10$ and at the FIFA Women's World Cup 2007. In his editorial pro memorial of Marc-Vivien Foé who suffered SCD during the FIFA Confederations Cup 2003, Dvorak ${ }^{12}$ stated that "a particular focus must be on youth competitors, who are often not sufficiently medically assessed prior to a major sporting event". For example, at the Confederation of African Football U-17 Cup 2009, ${ }^{11}$ in only three teams all their players had been examined before, while in other teams several players had never seen a physician before. Consequently, FIFA intended to introduce a mandatory PCMA for all players participating in its events. However, considering the financial and logistic problems that national football associations (FAs) might face with such requirements, it was decided to first evaluate the implementation of the PCMA at the arguably 'lowest' international level of play, the female youth World Cups.

The aim of this study was to assess the feasibility and compliance with performing a comprehensive PCMA in participating teams at the FIFA U-17 and U-20 Women's World Cups 2010.

\section{METHODS}

As there was no regulatory base for a mandatory requirement, the PCMA was 'highly recommended' to FAs participating in the respective World Cups by the FIFA Medical Committee. The FAs were asked to confirm in writing that the PCMA was performed in their players, and the submission of completed forms to FIFA was voluntary. No funding was provided by FIFA, but at the U-20 Women's World Cup, performance of echocardiography by a cardiologist was offered at the venues at no cost.

The standardised FIFA PCMA comprises personal and family history, general physical examination, laboratory blood analysis, and orthopaedic and cardiac examination (physical examination, 12-lead resting ECG and transthoracic echocardiography). ${ }^{9}$ Minor adaptations for female players included additional questions on menstrual history and calcium and ferritin levels.

In both the U-17 and the U-20 World Cup 2010, 16 teams with 21 players each (in total 672 players) from all six FIFA Confederations participated.

\section{RESULTS}

All U-20 teams (100\%) confirmed to have performed the PCMA in their players prior to the competition and seven FAs (43.8\%) submitted the forms to FIFA Medical Office. For 14 U-17 teams (87.5\%), the completed PCMA forms were submitted to the FIFA Medical Office. The PCMAs of one U-17 team were missing since the team physician claimed to have not received the respective information. One African FA had performed the PCMA of their U-20 players and stated thereafter not to have the financial means to perform PCMA in their U-17 team. All (except one) teams who submitted the forms used the FIFA PCMA form. In total, 147 PCMA forms of U-20 and 294 of U-17 players were received and analysed.

For African, Asian and Central/South American FAs, the team physician usually completed all sections, supervised and coordinated examinations by consultants (eg, cardiologists) and confirmed the eligibility to play themselves. Data were complete and presented in separate organised files per player and original data and reports (ECG and echocardiography) were provided with resulting excellent quality of data (particularly for U-17 teams). European and North American teams usually had several physicians from different institutions completing parts of the forms and signing the summary assessment. This resulted in highly variable completeness, presentation and quality of data. One European FA did not submit the FIFA 
PCMA form but submitted numerous different assessment forms, and for some players only the eligibility to play statement signed by a sports physician.

Personal and family history was completed for all players with no player reported to have any symptoms or signs of underlying disease. One African player reported what was understood as SCD in her father and was therefore submitted to follow-up. All players had normal physical cardiological examinations with a few systolic murmurs reported.

All teams had performed an ECG in their players (for one European team, the ECG performance could not be verified as the section was not completed). Twelve teams (57.1\%) provided the original ECG strips, others the automatic or the cardiologist's report instead or in addition. Six teams omitted completing the measurements when they provided strips or reports. Most frequently reported findings $(\mathrm{n}=17$; $3.9 \%)$ were incomplete right bundle branch blocks (RBBBs) and early repolarisation patterns. Two players had signs of ventricular hypertrophy on ECG; however, this is only based on voltage criteria, and one player each had signs of interspersed junctional rhythm or atrial extrasystoles. All four players had an additional echocardiography, in two players ventricular hypertrophy was confirmed by the cardiologist with no further pathological findings and cardiological follow-up recommended.

Six (85.7\%) U-20 and eight (57.1\%) U-17 teams who submitted their forms had performed an echocardiography on all players. In addition, three $(21.4 \%)$ U-17 teams had performed echocardiography only when indicated by abnormal findings in history, clinical examination or ECG. One African team performed echocardiography in all U-20 players but only where indicated in five U-17 players. The offer by FIFA to perform an echocardiography at the venue was only accepted by one of the teams who had not performed it prior to the competition at home; the others felt it interfered with their preparation schedule. One team refused because the cardiologist was a man.

Echocardiographic measurements were not always fully completed. Mostly, right ventricular and atrial as well as diastolic measurements were omitted. The majority of abnormal findings were mild-to-moderate regurgitation of the mitral, tricuspidal or pulmonary valve. Distribution and evaluation of these findings differed considerably: While no such finding was reported from other teams of the same confederation, the cardiologist of one U-17 reported eight pulmonary and one tricuspidal valve insufficiencies (and recommended all for follow-up without any further comment), and the cardiologist of one U-20 team considered the echocardiography as abnormal in eight players with regurgitation but recommended no follow-up. In addition, three U-17 players were reported to have signs of left ventricular hypertrophy, one player a thickened mitral valve and one player the surgical closure of an atrioseptal defect.

The summarising statements were duly completed in $64.3 \%$ of the U-17 teams and $85.7 \%$ of the U-20 teams. One team submitted an incomplete assessment of all players, and another team of 12 of their 21 players. Twelve (4.1\%) U-17 and five (3.4\%) U-20 players had no summarising assessment completed by the team physician. Nevertheless, declaration of eligibility was completed on all forms and all players were declared as eligible to play.

\section{DISCUSSION}

This report shares FIFA's experience with the implementation of a PCMA, as recommended in the International Olympic Committee consensus statement. ${ }^{3}$ The performance of a comprehensive PCMA in female youth football players at the international elite level proved feasible. Compliance with the requirement for performing a PCMA was high among all teams, particularly from Africa, Asia and Central/South America; this was reflected in the completeness and the presentation of data. While it is clear that specialists are required to perform particularly the cardiological assessments, quality of data was increased when the team physician collected all data and then personally completed/signed off the assessment forms as compared with when the specialists completed their respective section.

The clinical cardiological examination did not show any abnormal findings. Two-thirds of the teams performed an echocardiography in all players, and an additional $20 \%$ of the teams when indicated by clinical or ECG findings. Athletic ECG patterns (incomplete RBBB and repolarisation disturbances) but no abnormal findings were reported; very few findings were considered to require further investigation. Eight of the 12 players requiring cardiological follow-up came from one team, probably presenting an examiner-dependent bias. All players were declared as eligible to play.

The proven feasibility of performing comprehensive examination in all players at the 2006 FIFA World Cup, ${ }^{9}{ }^{10}$ the FIFA Women's World Cup 2007 and especially at the two female youth World Cups led to the decision of the FIFA Executive Committee to make the PCMA a compulsory requirement at all FIFA competitions.

Acknowledgements The authors appreciate the cooperation of all team physicians of the FIFA U-17 and U-20 World Cups in 2010 who gave of their time to collect the data for this project. The authors thank the FIFA Women's Department for their cooperation, especially Tatjana Hänni. The authors gratefully acknowledge FIFA (Fédération Internationale de Football Association) for the funding of the study and thank Anja König (FIFA) and Sonja Schlumpf (FIFA) for their administrative support.

Competing interests None.

Ethics approval Ethical approval was obtained from Kantonale Ethik-Kommission Zurich, Schweiz.

Provenance and peer review Not commissioned; externally peer reviewed.

\section{REFERENCES}

1. Best TM. The preparticipation evaluation: an opportunity for change and consensus. Clin J Sport Med 2004;14:107-8.

2. Wingfield K, Matheson GO, Meeuwisse WH. Preparticipation evaluation: an evidence-based review. Clin J Sport Med 2004;14:109-22.

3. Ljungqvist A, Jenoure P, Engebretsen L, et al. The International Olympic Committee (IOC) Consensus Statement on periodic health evaluation of elite athletes March 2009. Br J Sports Med 2009;43:631-43.

4. Corrado D, Pelliccia A, Bjornstad HH, et al. Cardiovascular pre-participation screening of young competitive athletes for prevention of sudden death: proposal for a common European protocol. Consensus Statement of the Study Group of Sport Cardiology of the Working Group of Cardiac Rehabilitation and Exercise Physiology and the Working Group of Myocardial and Pericardial Diseases of the European Society of Cardiology. Eur Heart J 2005;26:516-24.

5. Corrado D, Basso C, Schiavon M, etal. Pre-participation screening of young competitive athletes for prevention of sudden cardiac death. J Am Coll Cardiol 2008;52:1981-9.

6. Bille K, Figueiras D, Schamasch P, et al. Sudden cardiac death in athletes: the Lausanne Recommendations. Eur J Cardiovasc Prev Rehabil 2006;13:859-75.

7. Fuller CM, McNulty CM, Spring DA, et al. Prospective screening of 5,615 high school athletes for risk of sudden cardiac death. Med Sci Sports Exerc 1997;29:1131-8.

8. Maron BJ, Haas TS, Doerer JJ, et al. Comparison of U.S. and Italian experiences with sudden cardiac deaths in young competitive athletes and implications for preparticipation screening strategies. Am J Cardiol 2009;104:276-80.

9. Dvorak J, Grimm K, Schmied C, et al. Development and implementation of a standardized precompetition medical assessment of international elite football players-2006 FIFA World Cup Germany. Clin J Sport Med 2009;19:316-21.

10. Thünenkötter T, Schmied C, Grimm K, et al. Precompetition cardiac assessment of football players participating in the 2006 FIFA World Cup Germany. Clin J Sport Med 2009;19:322-5

11. Schmied C, Zerguini $Y$, Junge A, et al. Cardiac findings in the precompetition medical assessment of football players participating in the 2009 African Under-17 Championships in Algeria. Br J Sports Med 2009;43:716-21.

12. Dvorak J. A lion never dies: pro memoria of Marc-Vivien Foé. Br J Sports Med 2009;43:628 